\section{POTENTIAL PITFALLS OF PERIPHERAL NERVE BLOCKS IN PATIENTS WITH MUSCULAR DYSTROPHY: A REPORT OF TWO CLINICAL CASES}

1J Pinho*, ${ }^{2}$ D Pinho, ${ }^{2} \mathrm{~L}$ Coimbra. ${ }^{1}$ Francisco Gentil Portuguese Oncology Institute of Lisbon, Department of Anesthesiology, Lisbon, Portugal; ${ }^{2}$ Vila Nova de Gaia/Espinho Hospital Center, Department of Anesthesiology, Vila Nova de Gaia, Portugal

\subsection{6/rapm-2021-ESRA.205}

Background and Aims Muscular dystrophies are genetic disorders characterized by progressive muscular degeneration. Recommendations for the anesthetic management of these patients frequently include a preference for regional anesthesia and analgesia. Although case reports exist of peripheral nerve blocks in patients with muscular dystrophy, exceptionally few mention important difficulties that may be encountered. We aim to highlight these potential pitfalls.

Methods A thirteen-year-old boy with a diagnosis of Duchenne muscular dystrophy presented for equinovarus foot correction. $\mathrm{He}$ had tetraparesis and mild nocturnal hypoventilation. Intravenous anesthesia with target-controlled propofol and remifentanil infusions was combined with ultrasound guided popliteal sciatic and femoral nerve blocks.

A thirty-year-old man with a diagnosis of myotonic muscular dystrophy presented for patellar fracture and ligament reconstruction. He had an intellectual disability, stable hypoventilation syndrome and dysphagia. Ketamine sedation and a subarachnoid block were followed by ultrasound guided popliteal sciatic and femoral nerve blocks, and intraoperative soothing music.

Results Adequate analgesia was obtained without the use of long-acting or postoperative opioids. In the first case, altered muscular echostructure hampered identification of the adductor canal and femoral nerve. Patellar response to nerve stimulation was tenuous even when discomfort was elicited on injection. In the second case, sonographic visualization was unimpeded and nerve stimulation was not used to avoid triggering myotonia. Only light sedation was necessary.

Conclusions Although regional anesthesia is of benefit for patients with muscular dystrophy, potential pitfalls include
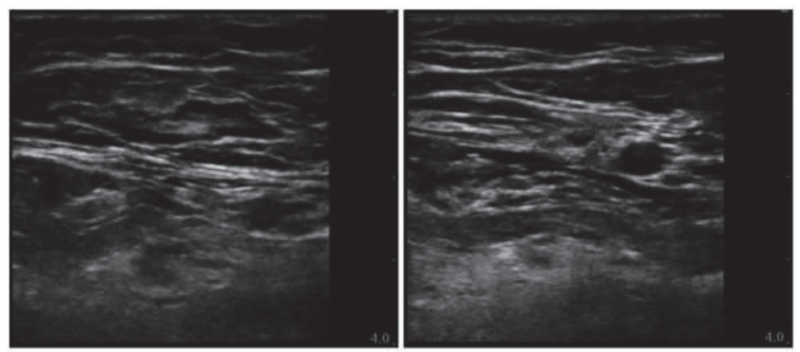

Abstract 205 Figure 1
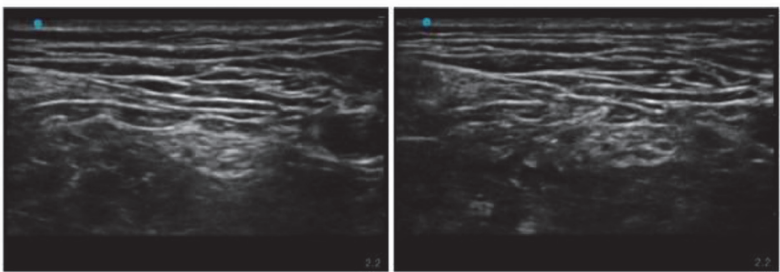

altered muscular echostructure, a decreased response to or the need to avoid nerve stimulation, and intellectual disability. Expert help should be considered if difficulties are encountered.

\section{PECTORAL NERVE AND PARASTERNAL BLOCK COMBINATION IN BREAST CANCER SURGERY: SUBCUTANEOUS MASTECTOMY WITH RECONSTRUCTION UNDER REGIONAL ANESTHESIA AND SEDATION. A CASE STUDY}

F Marrone*, S Paventi, M Tomei, M Bosco. ASL ROMA 1 - Ospedale Santo Spirito, Roma, Italy

\subsection{6/rapm-2021-ESRA.206}

Background and Aims US-guided pectoral nerve block may provide anaesthesia of lateral area of thorax, dermatomes T2T6. US-guided parasternal block may provide anaesthesia of medial area of breast. A combination of these blocks and sedation may be used in mastectomy especially in high risk patients.

Methods Patient aged-70, BMI 20; breast cancer $(5 \mathrm{~cm}$ triplenegative Ki50\%). Primary chemioterapy. Internal jugular vein thrombosis. Hypertension. Smoking. Anemia. ASA3. Subcutaneous mastectomy, sentinel lymph-node biopsy, reconstruction. After valid informed consent, anatomy and needle's tip correctly viewed, aseptically, US-PECS2 block was performed, $80-\mathrm{mm}$ echogenic needle; $0.5 \%$ ropivacaine $20 \mathrm{ml}$ were injected. US-PsB, second-fourth intercostal spaces, was performed; $50-\mathrm{mm}$ needle; $0.375 \%$ ropivacaine $4 \mathrm{ml}$ injected for each block. No complications. Pneumothorax excluded by LUS. Patient received IV midazolam $2 \mathrm{mg}+$ fentanyl $50 \mathrm{mcg}$; ketamine initial bolus $30 \mathrm{mg}(0,5 \mathrm{mg} / \mathrm{kg})$ then boluses, 90 $\mathrm{mg}$ in 2 hours, to induce and maintain light sleep with arousability. IV lydocaine $40 \mathrm{mg}$, clonidine $75 \mathrm{mcg}$, dexamethasone $8 \mathrm{mg}$ at beginning of surgery. IV lydocaine $2 \% 1 \mathrm{ml}$ $\mathrm{h}^{-1}$ was provided for 2 hours after initial bolus. Acetaminophen $1 \mathrm{~g}$ before awake. Spontaneous breathing and supplemental oxygen $40 \%$.

Results Monitored Anesthesia Care (MAC) was provided. Surgery began 15 minutes after MAC, 30 minutes after blockades placement. Surgery lasted 145 minutes, patient vital signs stable. No supplemental opioids or additional local

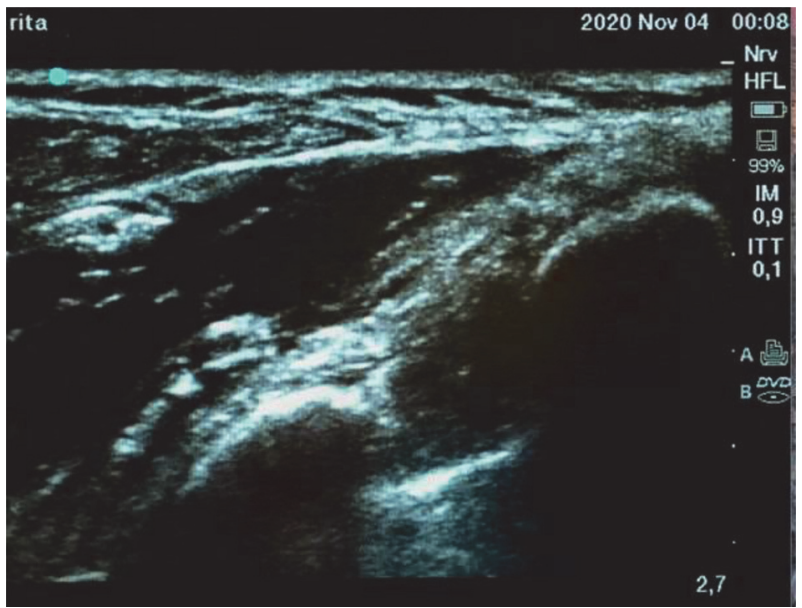

Abstract 206 Figure 1 


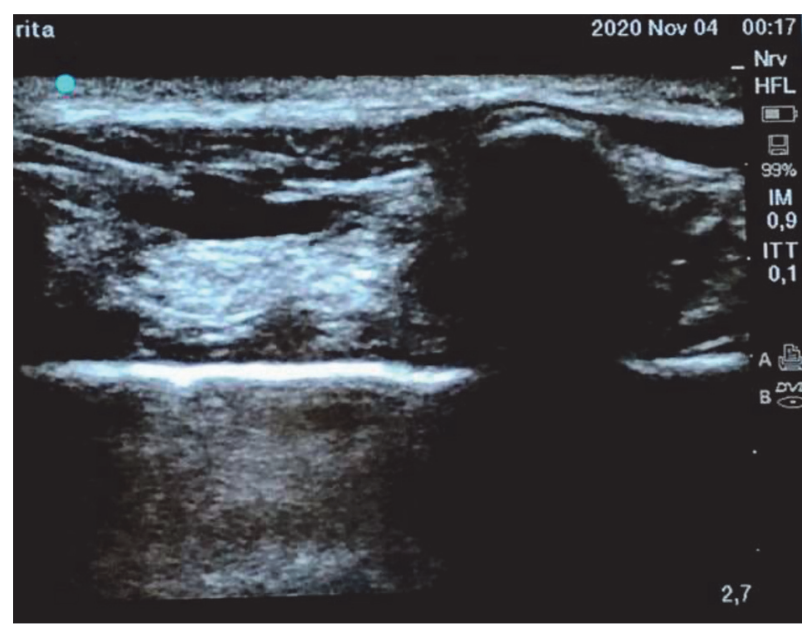

Abstract 206 Figure 2

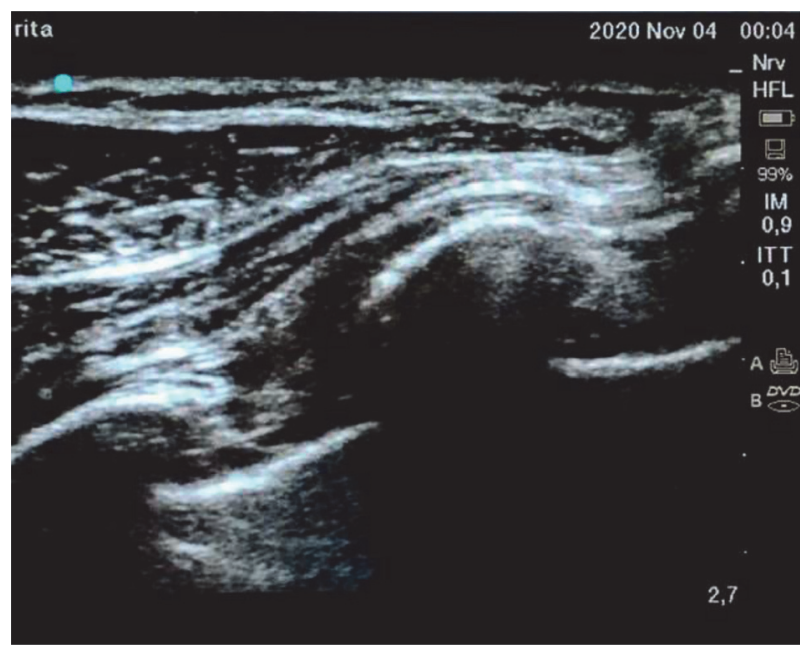

Abstract 206 Figure 3

anesthetics required during surgery. No pain (movement/rest). No morphine required. No peri-operative complications recorded.

Conclusions We performed US-guided inter-fascial plane blocks with high efficacy and safety. Our patient was successfully surgically treated. Regional anesthesia allowed early recovery, reduced postoperative opioid/non-opioid analgesics consumption together with early home discharge and cost reduction.

\section{IMPLEMENTATION OF TRAINING IN ULTRASOUND GUIDED REGIONAL ANAESTHETIC 'PLAN A' NERVE BLOCKS DURING THE COVID PANDEMIC - TRAINING MUST GO ON!}

F Moosa*, N Sadavarte, N Pinnamaneni, D Luff, A Hassan, N Bedforth. Nottingham University Hospitals NHS Trust, Nottingham, UK

\subsection{6/rapm-2021-ESRA.207}

Background and Aims There has been a significant impact on anaesthetic teaching and training within the UK owing to the COVID-19 pandemic. Most of the teaching needs are met using virtual methods. Hands on skills such as regional anaesthesia are not suitable for a virtual teaching format. Therefore, we aimed to continue and provide regional anaesthesia training in a large tertiary teaching hospital in a COVID-safe manner.

Methods We implemented training of 'Plan A' blocks'. This included dedicated theatre space, ultrasound equipment and use of HDMI technology for projection. The training was delivered in small groups in a safe and socially distanced manner. Information about the delivery of content, participant satisfaction and confidence in block performance were collected using a survey. All teaching was delivered by a Consultant and trainee with interest in regional anaesthesia. Approval was obtained form the local audit department.

Results Data was collated after a four-month cycle of teaching. Attendees ranged from core trainees (67\%) to junior registrars (33\%). 95\% participants found the content, hands on experience and presenters' knowledge to be excellent. $86 \%$ of participants felt they had better confidence in their block skills after the training. Overall satisfaction with delivery of the training was recorded as excellent in $95 \%$ of candidates.

Conclusions Continuing regional anaesthesia training in the COVID-19 pandemic has been beneficial for trainees in terms of improvement in skills and to boost their morale. This has been particularly relevant as there has been a drive to reduce aerosol generating procedures and improve safety for anaesthetists and theatre staff ${ }^{2}$.

\section{DISTAL NERVE BLOCKS FOR UPPER LIMB SURGERY: HIGH QUALITY, LOW VOLUMES}

C Lopes*, D Zuzarte, M Chedas. Centro Hospitalar de Lisboa Ocidental, Lisbon, Portugal

10.1136/rapm-2021-ESRA.208

Background and Aims Through this clinical case we aim to raise awareness of the existence of highly effective peripheral nerve blocks that allow to minimize the volume of local anesthetic, thus reducing the associated complications.

Methods A 20 year-old ASA I man was admitted for urgent reconstructive plastic surgery after left hand flexor tendon injury and right forearm extensor digitorium injury.

To offer anesthesia of the whole hand, we decided to perform a left axillary block. The right-limb wound was expected to be superficial and thus manageable under subcutaneous anesthetic infiltration.

When initiating the intervention on the right wound it was obvious that subcutaneous anesthesia was insufficient as the injury was deeper than predicted.

Faced with the fact that we had almost reached the toxic dose and that we were avoiding approaching the airway, we decided to perform an ultrasound guided distal-arm radial block, as the involved structures depended on radial sensory innervation.

Results A total amount of $3 \mathrm{ml}$ of local anesthetic was used.

The patient experienced complete anesthesia of the radial nerve territory, and surgery was successfully achieved. No complications were reported

Conclusions This approach reminds us that that, similar to the distal-arm radial block, there are numerous distal blocks that can be performed. While allowing a volume sparing technique, these blocks are both easy and safe to perform, offering high quality anesthesia and analgesia. 